\title{
PALATALIZAÇÃO NO PORTUGUÊS BRASILEIRO E NAS LÍNGUAS DO MUNDO: MOTIVAÇÃO ESTRUTURAL, SELEÇÃO DE GATILHOS E ALVOS
}

\author{
PALATALIZATION IN BRAZILIAN PORTUGUESE AND CROSS-LINGUISTICALLY: \\ STRUCTURAL MOTIVATION, SELECTION OF TRIGGERS AND TARGETS
}

\author{
Elisa Battisti \\ Universidade Federal do Rio Grande do Sul/CNPq \\ battisti.elisa@gmail.com \\ Ben Hermans \\ Meertens Institute/Vrije Universiteit-Amsterdam \\ ben.hermans@meertens.knaw.nl
}

Este artigo aborda a palatalização em português brasileiro (PB) e nas línguas do mundo, com os objetivos de esclarecer a motivação estrutural da palatalização, explicar por que as consoantes plosivas coronais são os alvos típicos do processo, por que são as únicas consoantes afetadas em PB e por que /i/, gatilho típico da palatalização, é a única vogal desencadeadora do processo nessa língua. Com elementos abstratos C e V (van der Hulst 2005, 2011), propomos uma estrutura interna de segmento para representar consoantes e vogais e mostrar que a consonantalidade dos vocoides anteriores altos motiva a palatalização, processo que tende a afetar consoantes de estrutura similar ao gatilho. Distinguem-se estruturalmente palatalização plena e secundária (Bateman 2007) e explica-se a seleção de gatilho e alvos da palatalização em PB como resultante do tipo mais restrito de palatalização plena, com alvo e gatilho maximamente idênticos.

Palavras-chave: palatalização; motivação estrutural; elementos $\mathrm{C}$ e V; estrutura interna de alvos e gatilhos.

Keywords: palatalization; structural motivation; elements C and V; internal structure of targets and triggers.

This paper is about palatalization in Brazilian Portuguese (BP) and cross-linguistically. It aims to show what the structural motivation of palatalization is, to explain why coronal stop consonants are the typical targets of palatalization, why they are the only targets of the process in BP, why /i/ is the typical trigger of palatalization and is the only trigger of the process in BP. With abstract elements C and V (van der Hulst 2005, 2011), we propose an internal structure of segments to show that the consonantality of high front vocoids is what motivates palatalization, a process that tends to affect consonants of similar structure to the trigger. We distinguish secondary and full palatalization (Bateman 2007) structurally and explain the selection of trigger and targets of palatalization in BP as the result of the most constrained kind of process, full palatalization with maximally identical trigger and targets. 


\section{Introdução}

Palatalização é o processo fonológico pelo qual consoantes adquirem articulação secundária palatal ou mudam seu ponto de articulação primário para a região palatal ou proximidades, geralmente sob influência de uma vogal anterior adjacente (Kochetov 2011). No português brasileiro (doravante PB), língua em que a palatalização é alofônica ${ }^{1}$ e tem aplicação categórica em quase metade das capitais brasileiras (Cardoso et.al. 2014) ${ }^{2}$, o processo seleciona como alvo as consoantes plosivas alveolares /t/ e /d/ e como gatilho a vogal anterior alta, tanto subjacente (1.a) quanto derivada de /e/ em sílabas átonas (1.b). O resultado são as africadas alveopalatais [t $\mathrm{d}$ d3].

(01) Palatalização em PB: exemplos

\begin{tabular}{|c|c|c|c|}
\hline a. Deser & da por /i/ subjacente & b. Dese & deada po \\
\hline tipo & ['t]ipo] & teatro & [t/i'atro] \\
\hline tijolo & {$\left[\mathrm{t} \int^{\prime} 1^{\prime} 30 l v\right]$} & noite & ['nojt $\mathrm{I}]$ \\
\hline prático & ['prat/iku] & & \\
\hline dicc & ['d3ike] & delic & [dzi'lisje] \\
\hline $\begin{array}{l}\text { dinheiro } \\
\text { médico }\end{array}$ & [dii'nerv] & onde & $\left.\left[' \tilde{o}^{11} \mathrm{~d}\right\} \mathrm{I}\right]$ \\
\hline & & & \\
\hline
\end{tabular}

O presente trabalho propõe-se a caracterizar alvo e gatilho do processo de palatalização de modo a esclarecer por que precisamente as consoantes $/ \mathrm{t} / \mathrm{e} / \mathrm{d} /$ agem como classe natural na palatalização em PB e por que somente /i/ desencadeia a palatalização nessa língua.

Responder essas questões implica relacionar a palatalização no PB aos padrões de palatalização nas línguas do mundo, ou à tipologia de palatalização, o que também se pretende fazer aqui. Em tal tipologia (Bateman 2007, Kochetov 2011), distinguem-se dois contextos de palatalização: morfofonológico (restrito a certas formas morfológicas) e fonológico (across the board, ou irrestrito morfologicamente). Distinguem-se também dois processos de palatalização em função de seus efeitos sobre a consoante-alvo: palatalização secundária (a consoante adquire articulação secundária) ${ }^{3}$ e palatalização plena (com mudança de ponto de articulação, ou de ponto e modo de articulação).

Em PB, o contexto de aplicação da palatalização é fonológico e verifica-se palatalização plena, com mudança de ponto e modo de articulação.

\footnotetext{
${ }^{1} \mathrm{O}$ presente estudo não trata de dois outros processos verificados em certas variedades de PB no mesmo contexto, mas que são de aplicação variável: a palatalização progressiva (Cristófaro-Silva 2003, Hora e Henrique 2015), como em

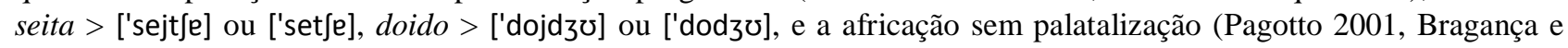
Azevedo 2015), como em Beti $>$ Be[ts]i.

${ }^{2} \mathrm{Na}$ outra parte das capitais brasileiras, segundo a mesma fonte (Atlas Linguístico do Brasil, de Cardoso et. al. (2014)), o processo é variável, o que coincide com análise anterior (Abaurre e Pagotto, 2002) de palatalização de /t d/ no português, também realizada com dados de fala dessas comunidades.

${ }^{3}$ Por exemplo, em russo, consoantes de todos os pontos de articulação podem ser palatalizadas antes de /e/, num processo geral de aquisição de articulação secundária palatal (posição alta frontal do corpo da língua) irrestrito em termos morfológicos. É o que explica Kochetov (2011: 1668), ilustrando o processo com as ocorrências a seguir (o símbolo $^{\mathrm{j}}$, sobrescrito logo após certas consoantes, registra palatalização secundária):

$\begin{array}{llll} & \text { nom } s g & \text { dat } s g & \\ \mathrm{p}-\mathrm{p}^{\mathrm{j}} & \text { trap-a } & \text { tra } \mathrm{p}^{\mathrm{j}}-\mathrm{e} & \text { 'caminho' } \\ \mathrm{t}-\mathrm{t}^{\mathrm{j}} & \text { sirat-a } & \mathrm{s}^{\mathrm{j}} \text { irar'-e }^{\mathrm{j}}-\mathrm{e} & \text { 'orfão' } \\ \mathrm{k}-\mathrm{k}^{\mathrm{j}} & \text { sabak-a } & \text { sabak }-\mathrm{e} & \text { 'cachorro' }\end{array}$
}


Nas línguas do mundo, conforme Bateman (2007), a vogal anterior alta /i/ e o glide palatal /j/ são os gatilhos típicos da palatalização, mas apenas o primeiro vocoide estabelece uma relação implicacional com outros possíveis desencadeadores do processo: se /e/ é gatilho da palatalização numa dada língua, /i/ também é. Os gatilhos da palatalização geralmente seguem o alvo (palatalização regressiva) e não são apagados. Os alvos típicos da palatalização são as consoantes /t $\mathrm{d} /$. Os alvos mais frequentes da palatalização plena são as consoantes /t d k g s n /, nessa ordem, e da palatalização secundária, /t d k g s n p b m/. Há uma implicação em relação aos alvos e o tipo de palatalização, secundária ou plena: se consoantes labiais são alvo da palatalização, elas sofrem somente palatalização secundária, e consoantes dorsais e coronais também são afetadas por palatalização plena ou secundária. Em PB, a palatalização afeta apenas as consoantes consideradas alvos típicos do processo e é desencadeada somente pelo gatilho típico.

Propostas prévias (Clements e Hume 1995, Morén 2003, van der Hulst 2005, por exemplo) de representação fonológica da palatalização nas línguas do mundo concebem o processo como espraiamento de traço de ponto de uma vogal anterior a uma consoante precedente, em geral plosiva, o que é teoricamente adequado. Entretanto, não fornecem a motivação estrutural do processo: guardada a tipologia da palatalização e os aspectos fonéticos (acústico-articulatórios) envolvidos no processo, a palatalização necessita ser explicada como um processo motivado pela constrição da vogal-gatilho (Bateman 2007, Kochetov 2011, Berns 2013), que tem efeitos sobre a consoante precedente.

O desafio é esclarecer por que o alto grau de constrição, ou consonantalidade, como defenderemos aqui, da vogal anterior alta desencadeia a palatalização. As propostas prévias sobre palatalização nas línguas do mundo tampouco explicam por que certos segmentos são melhores alvos do que outros, como também não distinguem entre diferentes tipos de palatalização (secundária e plena), o que procuraremos fazer.

No que se refere à palatalização em PB, análises prévias (Bisol e Hora 1993, Monaretto, Quednau e Hora 2005, Cristófaro-Silva 2003) não explicam por que somente plosivas coronais são alvos da palatalização nessa língua, tampouco por que somente a vogal anterior alta desencadeia o processo. Além disso, não representam a palatalização como um processo de mudança de estrutura (palatalização plena), ou representam-na como um processo em duas etapas, a primeira das quais (palatalização secundária) não se evidencia em PB.

A necessidade de dar conta dos aspectos acima expostos define, então, os objetivos da presente análise, que são:

(a) esclarecer a motivação estrutural da palatalização em PB e nas línguas do mundo;

(b) explicar por que as plosivas coronais e os vocoides altos são os alvos e os gatilhos típicos da palatalização;

(c) representar a palatalização secundária e a palatalização plena como processos estruturalmente distintos;

(d) explicar a seleção restrita de gatilho e alvos da palatalização em PB.

Como observa Kochetov (2011: 1686), a análise fonológica da palatalização tem desafiado os estudiosos devido, em parte, ao uso de representações de traço tradicionais, como a de Clements e Hume (1995), por exemplo. 
Este trabalho inspira-se numa teoria de organização de traço que se afasta dos modelos clássicos, a Fonologia CV Radical, de van der Hulst $(2005,2011)^{4}$. Como nesse modelo, emprega apenas os elementos $\mathrm{C}$ e $\mathrm{V}$, em lugar de traços, mas, diferentemente dele, não os combina na estrutura silábica, já que não a considera lexical. A proposta deste trabalho é combinar os elementos $\mathrm{C}$ e $\mathrm{V}$ numa estrutura interna de segmento organizada em nós equivalentes aos nós de classe na Geometria de Traço (Clements 1985 e outros estudos nessa linha). Tal concepção de estrutura interna de segmento e as combinações dos elementos $\mathrm{C}$ e $\mathrm{V}$ nas diferentes posições desses nós, a serem formalizadas na próxima seção, possibilitarão explorar nossas hipóteses de que (i) a motivação da palatalização está no caráter híbrido da vogal-gatilho - em sua consonantalidade, isto é, seu alto grau de constrição, a despeito de sua natureza vocálica - e de que (ii) a seleção dos alvos da palatalização relaciona-se à identidade estrutural entre vogal-gatilho e consoante-alvo do processo.

\section{Formalismo}

Em lugar de traços, usamos os elementos unários C e V (van der Hulst 2005, 2011), desprovidos de conteúdo fonético, e uma geometria única para representar a estrutura interna de vogais e consoantes. Embora falte concretude fonética aos primitivos fonológicos $\mathrm{C}$ e $\mathrm{V}$, eles relacionam-se a propriedades (acústicas e articulatórias) responsáveis por contrastes segmentais nos sistemas fonológicos. A interpretação das propriedades representadas por esses elementos deriva da posição que ocupam na estrutura fonológica, bem como de sua combinação com outros elementos naquela posição. Propomos que um segmento seja uma estrutura tripartite, de ramificação binária, sob um nó de raiz, como em (02).

(02) Estrutura interna dos segmentos

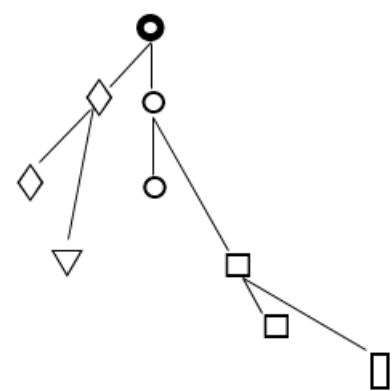

$(\mathbf{O}=$ posição de raiz; $\circ=$ posição de modo; $\square=$ posição de ponto; $\diamond=$ posição de fonação; $\square, \nabla=$ posições de ponto e fonação complexos. As posições são preenchidas com elementos $\mathrm{C}$ e V)

Consoantes são segmentos de raiz $\mathrm{C}$, vogais são segmentos de raiz V. De acordo com Botma (2004), tomamos Modo (posições o) como o cerne do segmento: é obrigatório, seleciona Ponto (posições $\square$ ) e Fonação (posições $\diamond$ ). Ponto é um dependente de Modo, Fonação é um especificador (o componente mais opcional). A ramificação extra de ponto e fonação $(\square, \nabla)$, embora estruturalmente possível, é muito restrita.

\footnotetext{
${ }^{4}$ A Fonologia CV Radical é uma das teorias de representação fonológica baseadas na ideia de que as relações de dependência são centrais na organização da estrutura fonológica. Essa ideia teve origem em dois modelos, o da Fonologia de Dependência (Anderson e Ewen 1987) e o da Fonologia de Governo (Kaye, Lowenstamm e Vergnaud 1985), que se desdobraram em outros modelos e hoje se apresentam em diferentes versões. As relações de organização usadas nessas abordagens são relações entre cabeças e dependentes, análogas às existentes entre constituintes sintáticos: o cabeça governa seus dependentes. Em vez de traços, os primitivos dessas abordagens são entidades monovalentes, unárias. Na Fonologia de Dependência, são denominados componentes, na Fonologia de Governo, elementos. Van der Hulst $(2005,2011)$ chama-os elementos, denominação que adotamos aqui.
} 
As posições de Modo, Ponto e Fonação na estrutura em (02) são preenchidas por elementos C e V. As diferentes combinações de elementos $\mathrm{C}$ e $\mathrm{V}$ nessas posições estruturais representam propriedades distintivas de consoantes e vogais, relevantes para expressar os contrastes numa dada língua. Em linhas gerais, C representa constrição/consonantalidade, V, sonoridade/vocalidade. Por exemplo, segmentos com algo grau de constrição, como as plosivas, têm as duas posições de Modo preenchidas por elementos C. Já fricativas, cujo grau de constrição é menor do que o de plosivas, têm uma de suas posições de Modo preenchida por elemento V. O mesmo vale para as posições de Ponto e Fonação, agora representando propriedades relativas a essas dimensões estruturais dos segmentos.

Em (03) está uma versão de combinações de elementos $\mathrm{C}$ e V suficiente para representar os contrastes segmentais relevantes à presente análise da palatalização em português brasileiro e outras línguas ${ }^{5}$. Em (3.a) estão combinações que representam propriedades de consoantes, segmentos de raiz C (Modo-C, Ponto-C, Fonação-C). Em (3.b) estão combinações que representam propriedades de vogais, segmentos de raiz V (Modo-V, Ponto-V, Fonação-V). Essa versão baseia-se grandemente em van der Hulst (2005), com algumas diferenças ${ }^{6}$.

(03) Propriedades segmentais representadas pelas combinações de elementos $\mathrm{C} \mathrm{e} \mathrm{V}^{7}$

(a)

\begin{tabular}{|l|l|l|c|}
\hline \multirow{2}{*}{ Modo- $C$} & \multirow{2}{*}{ Ponto- $C$} & \multicolumn{2}{c|}{ Fonação-C } \\
\cline { 3 - 4 } & & $\begin{array}{c}\text { Segmentos de Modo } \\
C \mathrm{C}, \mathrm{Cv}\end{array}$ & $\begin{array}{c}\text { Segmentos de } \\
\text { Modo } \mathrm{Vv}\end{array}$ \\
\hline $\mathrm{Cc}=$ plosividade & $\mathrm{Cc}=$ coronalidade & $\mathrm{Cc}=$ desvozeamento & $\mathrm{Cc}=$ nasalidade \\
\hline $\mathrm{Cv}=$ fricatividade & $\mathrm{Cv}=$ pós-coronalidade & $\mathrm{Cv}=$ murmúrio & \\
\hline & $\mathrm{Vc}=$ dorsalidade & $\mathrm{Vc}=$ laringalidade & \\
\hline $\mathrm{Vv}=$ soância & $\mathrm{Vv}=$ labialidade & $\mathrm{Vv}=$ vozeamento & \\
\hline
\end{tabular}

(b)

\begin{tabular}{|l|l|lr|}
\hline \multicolumn{1}{|c|}{ Modo- $V$} & \multicolumn{1}{c|}{ Ponto- $V$} & \multicolumn{2}{c|}{ Fonação-V (tom) } \\
\hline $\mathrm{Cc}=$ alto & $\mathrm{Cc}=$ anterioridade & $\mathrm{Cc}=$ alto & elevado \\
\hline $\mathrm{Cv}=$ médio alto & $\mathrm{Cv}=$ arredondamento anterior & $\mathrm{Cv}=$ alto & não-elevado \\
\hline $\mathrm{Vc}=$ médio baixo & $\mathrm{Vc}=$ anterioridade posterior & $\mathrm{Vc}=$ não-alto & elevado \\
\hline $\mathrm{Vv}=$ baixo & $\mathrm{Vv}=$ arredondamento posterior & $\mathrm{Vv}=$ não-alto & não-elevado \\
\hline
\end{tabular}

No que se refere a consoantes (3.a) e suas propriedades de Modo, Cc representa plosividade, $\mathrm{Cv}$, fricatividade, $\mathrm{Vv}$, soância. Nas propriedades de Ponto, $\mathrm{Cc}$ representa coronalidade, Cv, póscoronalidade, Vc, dorsalidade, Vv, labialidade.

\footnotetext{
${ }^{5}$ Nem todas as línguas apresentarão o conjunto inteiro de combinações. Na análise de uma dada língua, as combinações podem ser revisadas em relação às propriedades específicas que representam, dependendo dos contrastes existentes.

${ }^{6}$ As diferenças derivam principalmente do fato de não tomarmos a estrutura silábica como lexical e, assim, não distinguirmos entre combinações de Modo de Onset e combinações de Modo de Rima, por exemplo. A representação da nasalidade em consoantes nasais ainda está sob discussão: como em Botma (2004), poderia ser representada por um elemento V numa única posição de Fonação, desde que se tomassem essas consoantes como obstruintes em Modo (posições preenchidas por elementos $\mathrm{C}$ ). Até o presente momento e para fins desta análise, consideramos as consoantes nasais como soantes (segmentos $\mathrm{C}$ na raiz com ambas as posições de Modo preenchidas por elementos $\mathrm{V}$ ) $\mathrm{e}$ representamos a nasalidade em Fonação com elemento(s) C.

${ }^{7}$ Em nossa análise, como em van der Hulst $(2005,2011)$, a notação de uma combinação de elementos com maiúsculaminúscula (como Cc, por exemplo) representa cabeça-dependente. Embora essa relação não seja central na presente análise, ela é assumida aqui.
} 
Nas propriedades de Fonação, Cc representa desvozeamento, Vv, vozeamento em consoantes de Modo $\mathrm{Cc}$ e $\mathrm{Cv}$; em consoantes de Modo Vv, a combinação C(c) em Fonação representa nasalidade.

No que se refere a vogais (3.b) e suas propriedades de Modo, Cc representa alto, Cv, médio alto, Vc, médio baixo e Vv, baixo. Nas propriedades de Ponto, Cc representa anterioridade, Cv, arredondamento anterior, $\mathrm{Vc}$, anterioridade posterior, $\mathrm{Vv}$, arredondamento posterior. Nas propriedades de Fonação, as diferentes combinações representam distinções de tom.

Em (04) há exemplos da estrutura interna de algumas consoantes (4.a) e vogais (4.b).

(04) Exemplos

(a) plosividade

coronalidade

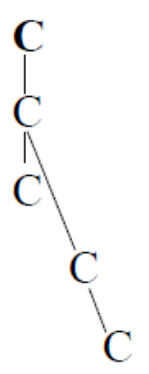

$/ \mathrm{t} /$

(b)
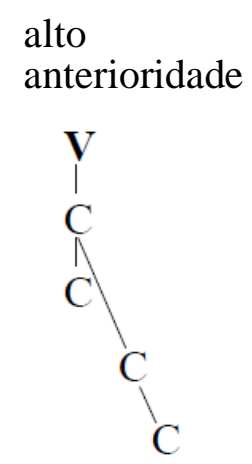

/i/ plosividade

dorsalidade

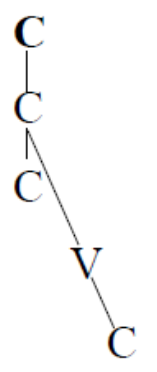

$/ \mathrm{k} /$

médio
anterioridade

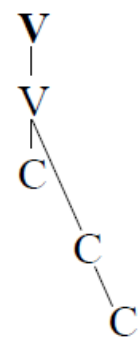

/e/ fricatividade

coronalidade

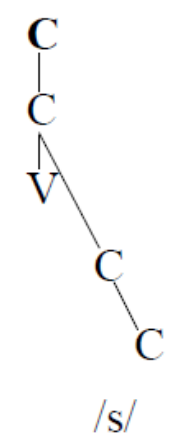

baixo

posterioridade

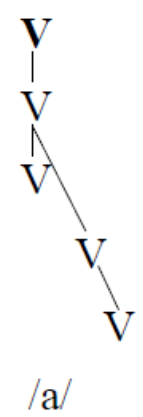

Com esse formalismo, nossa análise mostrará que o alto grau de constrição ou consonantalidade das vogais coronais é o motivador da palatalização, processo que afeta preferencialmente consoantes cuja estrutura interna seja o mais similar possível à vogal-gatilho.

\section{Análise}

\subsection{Os diferentes tipos de palatalização}

Há processos de palatalização estruturalmente distintos - palatalização secundária e plena porque Ponto é uma estrutura ramificada. A palatalização pode resultar ou do espraiamento de um dos elementos de Ponto da vogal (palatalização secundária, 5.a), ou do espraiamento de toda a ramificação de Ponto da vogal à consoante precedente (5.b). 
(05) Palatalização: esquema geral

a. Palatalização secundária

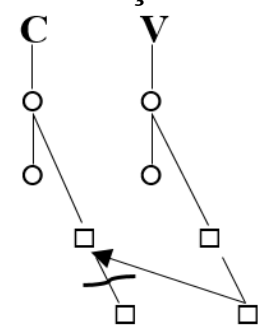

b. Palatalização plena

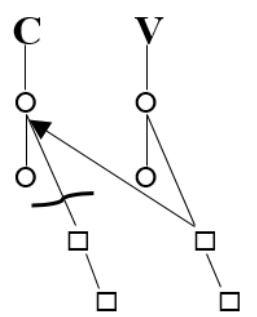

Nossa expectativa é a de que elementos $\mathrm{C}$ de vogais espraiem para consoantes cujas posições estruturais sejam também preenchidas com elementos C. Isso dá origem ao que chamamos 'mudança sem mudança': o desligamento do elemento $C$ de uma posição consonantal, a ser preenchida com o elemento $\mathrm{C}$ da vogal, é mais uma substituição do que uma mudança, como se vê em (06).

(06) 'Mudança sem mudança'

a. Palatalização secundária

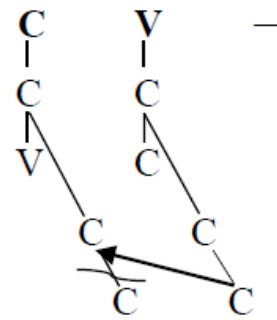

/s/ /i/

b. Palatalização plena

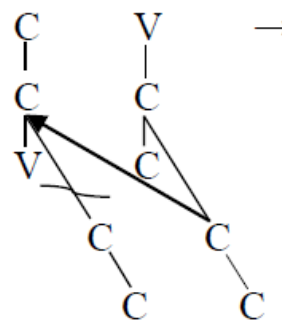

/s/ /i/

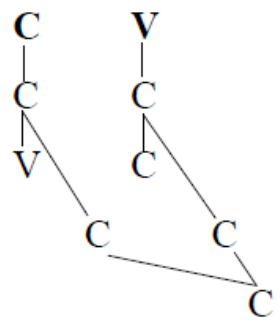

$\left[\mathrm{s}^{\mathrm{j}} \mathrm{i}\right]$ 
Alvo e gatilho no exemplo (06) são minimamente diferentes - ambos têm Ponto Cc, mas o alvo tem Modo $\mathrm{Cv}$ e o gatilho, Modo Cc. Os alvos podem diferenciar-se ainda mais do que isso, mas, à medida que aumentam as diferenças entre gatilho e consoante precedente, reduz-se a possibilidade de essa ser afetada pelo processo. Propomos que a palatalização favoreça alvos que sejam similares ao gatilho, no espírito da 'mudança sem mudança'.

Gatilho e alvo da palatalização podem ser maximamente idênticos. Nesse caso, todos os elementos $\mathrm{C}$ da vogal podem espraiar para a consoante precedente, e uma outra operação de palatalização plena é possível, como ilustra o esquema geral em (07).

(07) Palatalização plena envolvendo alvo e gatilho totalmente idênticos (em Modo e Ponto)

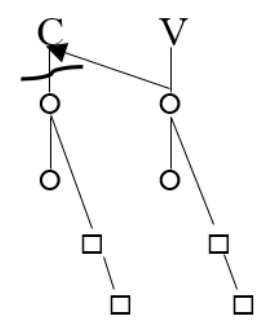

Esse tipo de palatalização só é possível com gatilho /i/ e alvos /t d/, como se vê em (08).

(08) Palatalização com gatilho /i/ e alvos /t d/

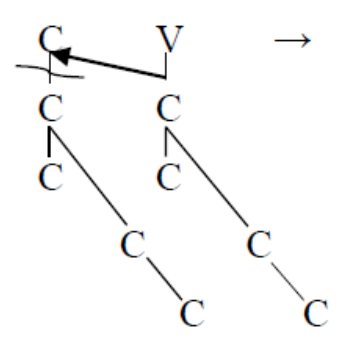

$/ \mathrm{t} / \quad / \mathrm{i} /$

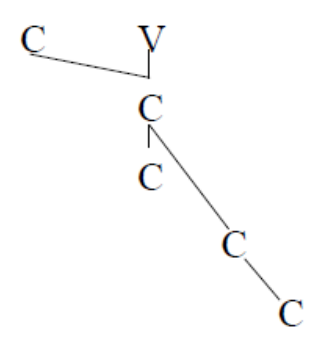

$[\mathrm{t} f \mathrm{i}]$

No entanto, às vezes algumas posições relevantes das consoantes-alvo são preenchidas com elementos V. Nesse caso, dois resultados do espraiamento de C são possíveis: a manutenção dos elementos $\mathrm{V}$ da consoante-alvo, de que resulta palatalização secundária e se dá origem a uma estrutura complexa, como esquematizado em (9.a) e exemplificado em (9.a.i); e o desligamento dos elementos $\mathrm{V}$ do alvo, de que resulta palatalização plena com mudança, como no esquema geral em (9.b) e no exemplo em (9.b.i).

(09) Palatalização que origina estruturas complexas e palatalização com mudança

a. Palatalização secundária

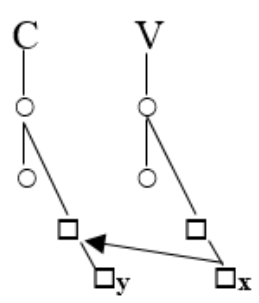

b. Palatalização plena

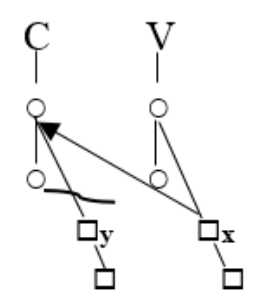




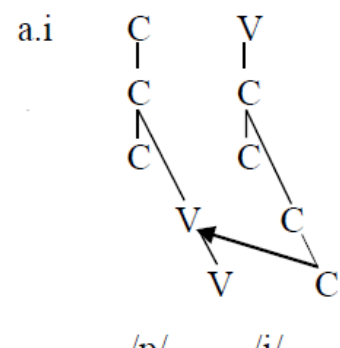

$/ \mathrm{p} / \quad / \mathrm{i} /$

b.i

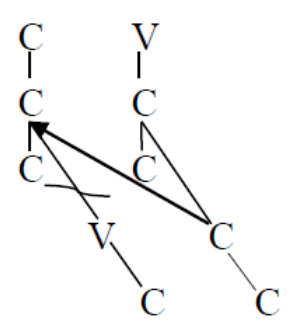

/k/ /i/

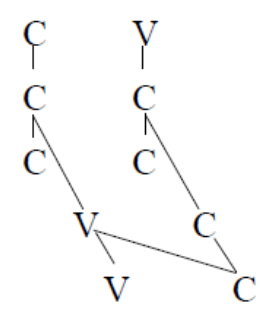

$\left[\mathrm{p}^{\mathrm{j}} \mathrm{i}\right]$

Propomos que, embora possíveis, tanto a palatalização com mudança quanto a palatalização que origina estruturas complexas sejam processos desfavorecidos.

3.2 A motivação estrutural da palatalização, gatilhos e alvos típicos

A vogal /i/ é o gatilho típico da palatalização devido à sua natureza consonantal, correspondente a seu alto grau de constrição: ambas as posições de Modo e de Ponto de /i/ são preenchidas com elementos $\mathrm{C}$ em função da altura (/i/ é uma vogal alta) e da coronalidade (/i/ é uma vogal anterior). É nesse sentido que concebemos /i/ como uma vogal 'híbrida': é um segmento de raiz V (vogal) com todas as posições (de Modo e Ponto) preenchidas por elementos C, como se representa em (10).

(10) A natureza híbrida da vogal anterior alta

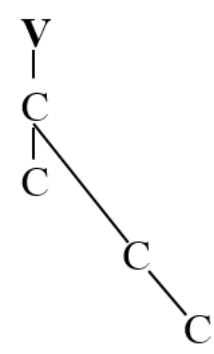

Vogais são segmentos de raiz V e consoantes são segmentos de raiz C. De acordo com van der Hulst (2005), segmentos de raiz V favorecem elementos V em sua estrutura, segmentos de raiz $\mathrm{C}$ favorecem elementos $\mathrm{C}$ em sua estrutura. Propomos que os elementos $\mathrm{C}$ de um segmento de raiz $\mathrm{V}$, como a vogal anterior alta, tendam a se espraiar para a consoante precedente (segmento de raiz C) de modo a ser apropriadamente licenciados. Em outras palavras, nós explicamos a palatalização como o espraiamento de elementos $\mathrm{C}$ de vocoides anteriores altos para a consoante precedente para obter licenciamento apropriado. Essa é a motivação da palatalização, que expressamos em (11). 
(11) Palatalização por /i/

PAL

Os elementos C de uma vogal com Modo e Ponto Cc devem ser licenciados por uma consoante.

Outras vogais (a média anterior /e/ e a alta posterior /u/) podem desencadear palatalização, mas respeitando a implicação de que a vogal anterior alta também seja gatilho do processo (Bateman 2007, Kochetov 2011). Isso se explica pelo fato de que a vogal média é anterior (coronal), mas não é tão consonantal quanto /i/ no que se refere a Modo (altura), como se vê em (12). Já a vogal /u/, raro gatilho da palatalização, representada em (13), é tão alta quanto /i/, mas não é anterior (coronal). É menos consonantal do que $/ \mathrm{i} / \mathrm{e} / \mathrm{e} /{ }^{8}$.

(12) Vogal média anterior: Ponto Cc, mas Modo Vc

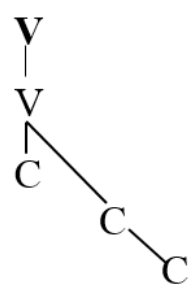

(13) Vogal alta posterior: Modo Cc, mas Ponto Vv

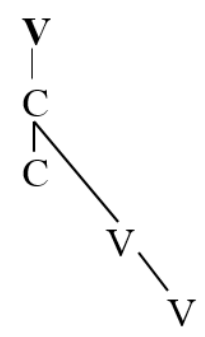

Em relação aos alvos da palatalização, as consoantes plosivas coronais apresentam-se como alvos típicos porque são segmentos altamente consonantais. Elas são Cc tanto em Ponto quanto em Modo, como se vê em (14).

(14) Plosivas coronais

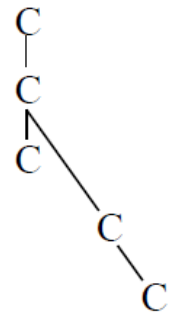

$/ \mathrm{t} /$

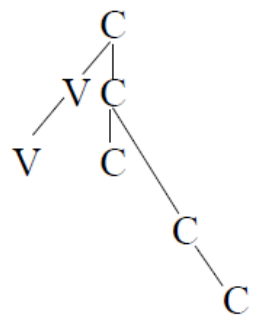

$/ \mathrm{d} /$

\footnotetext{
${ }^{8}$ A altura (Modo) deve ser a propriedade de /u/ em jogo na palatalização. Isso implica o espraiamento de Modo, mas não de Ponto, o que nossa proposta, tal qual se apresenta neste trabalho, não explica. Esse fato deverá merecer atenção em análise futura.
} 
A estrutura interna das plosivas coronais torna-as maximamente idênticas ao gatilho típico da palatalização em termos elementais. Nós assumimos que a palatalização de /t d/ por /i/ seja uma expressão da 'mudança sem mudança', ou máxima identidade entre gatilho e alvo da palatalização: as plosivas coronais são os alvos preferidos da palatalização porque são maximamente consonantais e idênticos, em termos elementais, ao gatilho típico. Como consequência, o grau de mudança causada pelo espraiamento-desligamento de elementos de Ponto e Modo é minimizado, porque os elementos envolvidos são os mesmos, como se vê em (15).

(15) Mudança sem mudança: palatalização plena de plosiva coronal

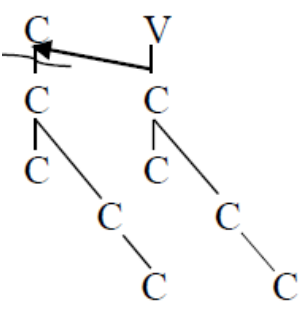

$/ \mathrm{t} / \quad$ i $/$

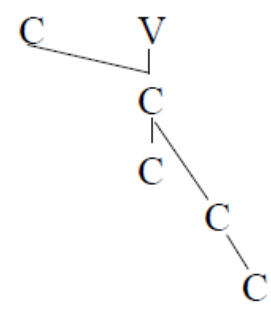

[ci] ou [tfi]

Já as plosivas dorsais $/ \mathrm{k} \mathrm{g} /$, representadas em (16), são os segundos melhores alvos de palatalização porque são um pouco menos consonantais do que as plosivas coronais.

(16) Plosivas dorsais: Modo Cc, mas Ponto Vc

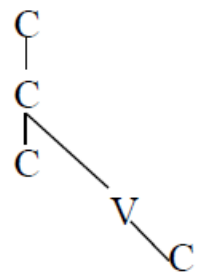

$/ \mathrm{k} /$

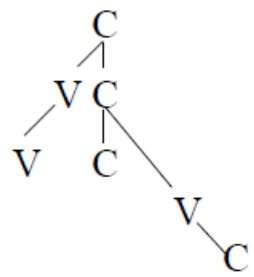

$/ \mathrm{g} /$

Essa configuração interna faz com que a palatalização (plena) de plosivas dorsais cause mudança de elemento, como se vê em (17), operação que tende a ser desfavorecida.

(17) Palatalização plena de plosiva dorsal

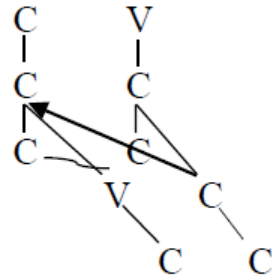

$/ \mathrm{k} / \quad / \mathrm{i} /$<smiles>CC(C)C1C(C)C1C</smiles>

[ci] ou [t $\mathrm{fi}]$

O grau de semelhança elemental entre gatilho e alvo explica também porque obstruintes (plosivas mais do que fricativas) são melhores alvos de palatalização do que nasais, seguidas de laterais e, finalmente, de róticos. Como se vê em (18), obstruintes são mais consonantais do que os outros tipos de segmento: das obstruintes aos róticos, passando por fricativas, nasais e laterais, os segmentos aumentam seu caráter vocálico. 
(18) Estrutura de uma consoante plosiva, uma fricativa, uma nasal, uma lateral, um rótico

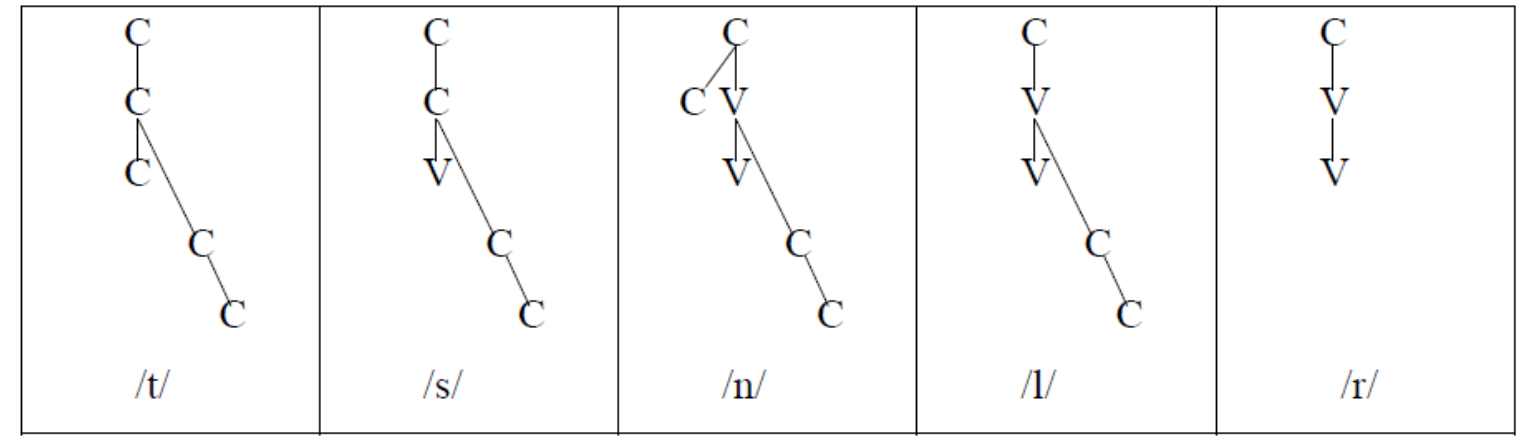

A palatalização causa menos mudança em obstruintes do que em outros segmentos.

Nós prevemos que padrões como esse, que selecionam gatilhos estruturalmente similares aos alvos, manifestem-se em outros processos assimilatórios. É o que deve ocorrer na labialização, por exemplo: espera-se que vogais posteriores arredondadas (de Ponto Vv) tendam a afetar consoantes labiais e dorsais, que têm Ponto Vv e Vc, respectivamente, com o espraiamento de pelo menos um dos elementos $\mathrm{V}$ da vogal para a consoante. A análise da labialização em espanhol judaico (Bradley 2015: 66) confirma essa expectativa e mostra que a língua exibe tendências de outras línguas do mundo: coronais tendem a evitar labialização secundária, enquanto labiais e especialmente dorsais são alvos favorecidos.

Nesse sentido, compreende-se por que as consoantes labiais sofrem apenas palatalização secundária: elas têm Ponto Vv. Apenas um elemento de Ponto $\mathrm{Cc}$ da vogal anterior pode espraiar. Não ocorre desligamento de traço. O resultado, representado em (19), é uma estrutura complexa, que emerge do único tipo de palatalização possível, a secundária.

(19) Palatalização secundária de plosiva labial

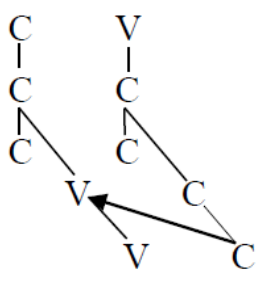

$/ \mathrm{p} / \quad / \mathrm{i} /$

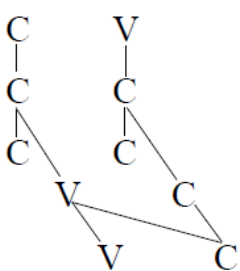

$\left[\mathrm{p}^{\mathrm{j}} \mathrm{i}\right]$

3.3 A seleção de gatilho e alvos da palatalização em PB

A vogal /i/ é o único gatilho da palatalização em PB porque essa língua impõe uma exigência: a de que gatilho e alvos sejam maximamente consonantais e, assim, idênticos.

(20) Palatalização por /i/ com alvo maximamente idêntico

\section{PAL/MAXIDENT}

Os elementos $\mathrm{C}$ de uma vogal com Modo $\mathrm{Cc}$ e Ponto $\mathrm{Cc}$ devem ser licenciados por uma consoante de Modo Cc e Ponto Cc.

Palatalização em PB, como em outras línguas que selecionam apenas /i/ como gatilho e /t d/ como alvo, é altamente restrita. Nós repetimos (08) in (21). 
(21) Palatalização em PB

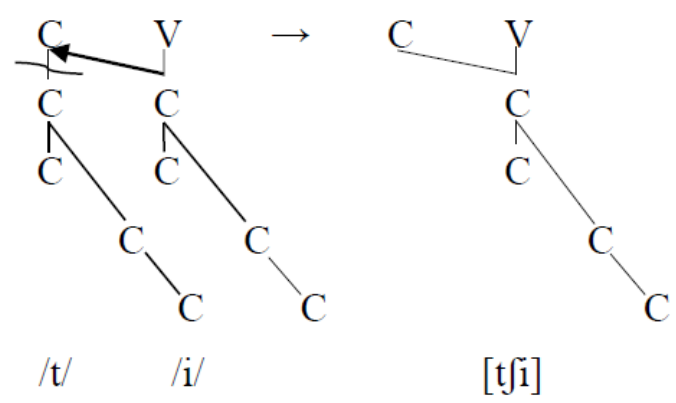

$\mathrm{O}$ PB seleciona /i/ e /t d/ como gatilho e alvos, respectivamente, porque resulta do tipo mais restrito de processo, o que requer máxima identidade entre gatilho e alvo, satisfazendo plenamente 'mudança sem mudança'. Na perspectiva de uma teoria de processamento da gramática como a OT (Optimality Theory, de Prince e Smolensky, 1993/2004), tal seleção resulta do ordenamento de uma restrição como PAL/MAXIDENT acima de uma restrição de fidelidade como IDENT/Element e, essas duas, acima da restrição mais geral de palatalização, PAL.

\section{Conclusão}

Nossa análise mostrou que tanto a motivação quanto a seleção de alvos e gatilho da palatalização em PB têm razões estruturais e enquadram-se na tipologia de palatalização nas línguas do mundo.

Propusemos que a motivação da palatalização é o alto grau de consonantalidade dos vocoides anteriores altos: esses segmentos, gatilhos típicos do processo, têm tanto as posições de Ponto quanto as de Modo preenchidas com elementos C. Como elementos $\mathrm{C}$ são desfavorecidos em segmentos de raiz $\mathrm{V}$, os elementos $\mathrm{C}$ de vocoides anteriores altos tendem a espraiar para a consoante precedente, de modo a serem propriamente licenciados.

Mostramos que as plosivas coronais são os alvos típicos da palatalização porque são altamente consonantais e, assim sendo, são maximamente idênticas (em termos elementais) ao gatilho típico. Isso expressa o que denominamos 'mudança sem mudança': a mudança resultante do espraiamento e desligamento de elementos é minimizada porque os elementos envolvidos no processo são intrinsecamente os mesmos. Uma consequência desse princípio é a de que consoantes mais similares ao gatilho típico em sua estrutura interna serão afetadas pela palatalização com mais frequência.

A análise prevê, assim, que plosivas coronais sejam preferidas a velares e a labiais como alvos da palatalização. Entre as plosivas velares e labiais, prevê que velares sejam os alvos preferidos. Entre obstruintes e soantes, que as obstruintes sejam preferidas. No que concerne ao gatilho da palatalização, a análise prevê que a /i/ seja o melhor desencadeador do processo.

Nossa proposta está de acordo com a de Clements e Hume (1995) no que diz respeito aos elementos de Ponto $(\mathrm{Cc})$ que espraiam, correspondentes ao traço [coronal] no nó de Ponto da vogal, na proposta daqueles autores. Conforma-se também à de Bateman (2007) no que se refere à especificação da vogal-gatilho típica como [palatal, estreito] (pela Fonologia Articulatória), o que representamos com Modo Cc. Integramos, portanto, essas duas propostas numa só, mas, diferentemente delas, explicamos, com os elementos $\mathrm{C}$ e $\mathrm{V}$, fatos tipológicos de modo puramente fonológico (abstrato). 
Em relação ao processo, distinguimos estruturalmente dois tipos de palatalização, secundária e plena, e as analisamos de forma unificada. A palatalização secundária resulta do espraiamento de um dos elementos de Ponto da vogal-gatilho. A palatalização plena resulta do espraiamento de ambos os elementos de Ponto, o que acaba afetando Modo da consoante-alvo. Um outro tipo de palatalização plena, mais restritivo, é possível quando gatilho e alvo são maximamente idênticos: emerge do espraiamento de Ponto e Modo da vogal, como um todo, para a consoante precedente. Esse último tipo de palatalização é o que afeta as plosivas coronais em PB. Relaciona-se ao fato de a exigência de máxima identidade ser satisfeita na língua, com a seleção de $/ \mathrm{i} / \mathrm{e} / \mathrm{t} \mathrm{d} / \mathrm{como}$ únicos gatilho e alvos da palatalização, respectivamente.

Nossa proposta tem potencial para explicar dois processos variáveis e pouco frequentes, mas possíveis em $\mathrm{PB}$, de que não pudemos tratar aqui: a palatalização de $/ \mathrm{t} \mathrm{d} /$ por glide palatal $^{9}$ precedente, muito provavelmente resultante de metátese (seita ['sejtfe], ['setfe]; doido ['dojdzo], ['dod3v]), e a africação ou assibilação de /t d/ por vocoide anterior alto seguinte. Esse último processo parece afetar apenas Modo da consoante-alvo, o que desafia nossa proposta de estrutura interna de segmento e de operações de espraiamento possíveis. Analisar esses processos e seguir testando as vantagens e limites do modelo proposto serão desdobramentos futuros deste trabalho.

\section{Referências}

Abaurre, Maria Bernadete e Emílio Gozze Pagotto. 2002. Palatalização das oclusivas dentais no português do Brasil, em M. B. Abaurre e A. C. S. Rodrigues (organizadores), Gramática do Português Falado Volume VIII: novos estudos descritivos, Campinas/SP, Editora da UNICAMP: 557-602.

Anderson, John Mathieson e Colin J. Ewen. 1987. Principles of dependency phonology, Cambridge, Cambridge University Press.

Bateman, Nicoleta. 2007. A crosslinguistic investigation of palatalization, Tese de Doutorado, University of California, San Diego. Inédita.

Berns, Janine. 2013. Friction between phonetics and phonology: the status of affricates, Tese de Doutorado, Radboud Universiteit, LOT, Utrecht.

Bisol, Leda e Dermeval da Hora. 1993. Palatalização da oclusiva dental e fonologia lexical, em Actas do IX Encontro da Associação Portuguesa de Linguística: 61-80.

Botma, Engbert Doede. 2004. Phonological aspects of nasality: An element-based dependency approach, Tese de Doutorado, University of Amsterdam, LOT, Utrecht.

Bradley, Travis G. 2015. Labialization and palatalization in Judeo-Spanish phonology, em J. Smith e T. Ihsane (eds.), Romance Linguistics 2012. Selected papers from the 42nd Linguistic Symposium on Romance Languages (LSRL), Amsterdam/Philadelphia, John Benjamins: 6383.

Bragança, Marcela Langa Lacerda e Lilian Keide Arnhold de Azevedo. 2015. Variação como espaço de investigação identitária: análise de uma pequena rede social familiar feminina de Florianópolis/SC, em R. M. K. Freitag e C. G. Severo (orgs.), Mulheres, linguagem e poder Estudos de gênero na sociolinguística brasileira, São Paulo, Blucher: 109-128.

Cardoso, Suzana Alice Marcelino da Silva e Jacyra Andrade Mota, Vanderci de Andrade Aguilera, Maria do Socorro Silva de Aragão, Aparecida Negri Isquerdo, Abdelhak Razky, Felício Wessling Margotti, Cléo Vilson Altenhofen. 2014. Atlas linguístico do Brasil, Londrina, EDUEL.

\footnotetext{
${ }^{9}$ Não há consenso, na literatura sobre fonologia do PB, acerca da existência de glides subjacentes.
} 
Clements, George Nick. 1985. The geometry of phonological features, Phonology Yearbook, 2: 225-252.

Clements, George Nick e Elizabeth Valerie Hume. 1995. The internal organization of speech sounds, em J. A. Goldsmith (ed.), The handbook of phonological theory, Cambridge, Massachusetts/Oxford, Blackwell: 245-306.

Cristófaro-Silva, Thaïs. 2003. Palatalization in Brazilian Portuguese, em S. Ploch (ed.), Living on the edge: 28 papers in honour of Jonathan Kaye. Studies in Generative Grammar 62, Berlin/New York, Mouton de Gruyter: 243-257.

Hora, Dermeval da e Pedro Felipe de Lima Henrique. 2015. Processos de assimilação envolvendo as consoantes oclusivas dentais /t, d/ no português brasileiro, Signum: Estudos da linguagem, 18/1: 206-230.

Kaye, Jonathan Derek, Jean Lowenstamm, e Jean Roger Vergnaud. 1985. The internal structure of phonological elements: A theory of charm and government, Phonology, 2: 305-328.

Kochetov, Alexei. 2011. Palatalization, em M. van Oostendorp, C. J. Ewen, E. V. Hume e K. Rice (eds.), The Blackwell companion to phonology, Malden/Oxford/West Sussex: Blackwell: 1666-1690.

Monaretto, Valéria Neto de Oliveira, Laura Quednau e Dermeval da Hora. 2005. As consoantes do português, em L. Bisol (organizadora), Introdução a estudos de fonologia do português brasileiro, Porto Alegre, EDIPUCRS: 207-238.

Morén, Bruce. 2003. The parallel structures model of feature geometry, Working papers of the Cornell Phonetics Laboratory, 15: 194-270.

Pagotto, Emilio Gozze. 2001. Variação é identidade, Tese de Doutorado, Universidade Estadual de Campinas, Campinas. Inédita.

Prince, Alan e Prince Smolensky. 1993/2004. Optimality theory: Constraint interaction in generative grammar. Disponível em http://roa.rutgers.edu/files/537-0802/537-0802-PRINCE-00.PDF

van der Hulst, Harry. 2005. The molecular structure of phonological segments, em P. Carr, J. Durand e C. J. Ewen (eds.), Headhood, elements, specification and contrastivity: phonological papers in honour of John Anderson, Amsterdam/Philadelphia, John Benjamins: 193-234.

van der Hulst, Harry. 2011. Dependency-based phonologies, em J. Goldsmith, J. Riggle e A. C. L. $\mathrm{Yu}$ (eds.), The handbook of phonological theory, Malden/Oxford, Wiley-Blackwell: 533-570. 